\title{
РАСПРЕДЕЛЕНИЕ СЕРЫ ПРИ ТЕРМИЧЕСКОЙ ПЕРЕРАБОТКЕ КУКЕРСИТА В УСТАНОВКАХ С ТВЕРДЫМ ТЕПЛОНОСИТЕЛЕМ
}

В последние годы в Эстонской ССР проводятся предпромышленные испытания метода термической переработки мелкозернистого сланца в установке с твердым теплоносителем (УТТ) на предмет его энерготехнологического использования. Ранее этот метод опробовался на ряде установок различной мощности [']. Накопленные при этом материалы полезно рассмотреть и в столь важном аспекте, как подготовка к организации мер по защите окружающей среды в случае промышленной реализации метода.

Кукерсит содержит ряд разновидностей сернистых соединений $\left[{ }^{2,3}\right]$, из которых наиболее значительна пиритная сера (до $50-70 \%$ от общей серы). Их природа, наряду с особенностями технологического процесса, оказывает существенное влияние на трансформацию и распределение серы в процессе переработки.

Основные технологические этапы УТТ [']: подогрев и сушка сланца дымовыми газами в аэрофонтанной сушилке (АФС); термическое разложение его в реакторе после смешения с зольным теплоносителем; сжигание твердого остатка в аэрофонтанной топке (АФТ). Выбранный температурный режим, а также избыток воздуха в АФТ определяют протекание и соотношение первичных и вторичных реакций разложения и превращения исходной серы.

В табл. 1 приведен общий баланс распределения серы по разновидностям в процессе полукоксования кукерсита $\left(A^{d}=48,50 \% ; \quad\left(\mathrm{CO}_{2}\right)_{M}^{d}=\right.$ $15,80 \%$ ) в пилотной установке при типовом режиме: температура в АФС $T_{c}=225^{\circ} \mathrm{C}$, температура смеси материалов на выходе из реактора $T_{\mathrm{p}}=$ $515^{\circ} \mathrm{C}$, в нижней части АФТ $-750^{\circ} \mathrm{C}$ и в верхней ее части $-875^{\circ} \mathrm{C}$, коэффициент избытка воздуха $(\alpha)-1,2$, производительность по сланцу $-100 \mathrm{kr} /$ ч. Данные по неопределяемому стандартными методами количеству серы характеризуют в основном серу органического происхождения.

Значительная доля (около $65 \%$ ) исходной серы переходит в твердый остаток переработки, причем в основном в сульфатной $(39,9 \%)$ и суль-

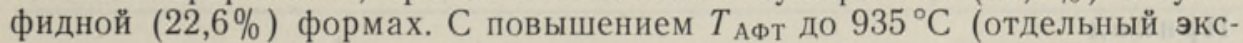
перимент) содержание сульфидов в золе снижается до $0,75 \%$ против $1,23 \%$ в случае типового режима и происходит практически полное разложение пиритной серы $(0,02 \%)$.

Причина этого явления раскрывается при сопоставлении этих данных с балансом серы при полукоксовании диктионемового сланца месторождения Маарду, проведенного нами в тех же условиях (общая сера $2,85 \%$, сульфатная - $0,45 \%$, пиритная - $1,97 \%$ и органическая $0,43 \%$; в золе: общая сера - $0,23 \%$, сульфатная - $0,13 \%$, сульфидная лишь $0,03 \%$ и пиритная - $0,02 \%$ ). В его минеральной части практически отсутствуют карбонаты кальция и магния (карбонатного $\mathrm{CO}_{2}$ менее $0,5 \%)$, что исключает связывание сернистых компонентов летучих мате- 
Общий баланс распределения серы в процессе переработки кукерсита в пилотной установке

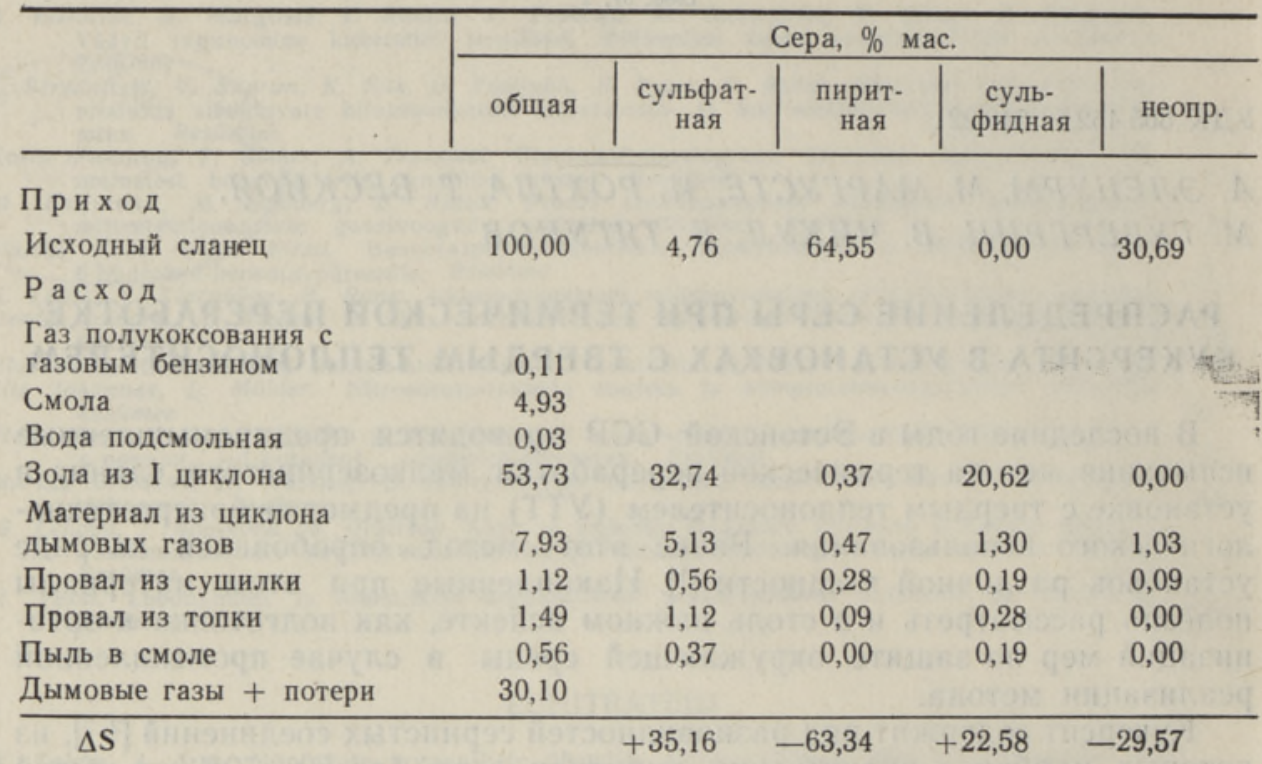

риалом теплоносителя в реакторе и формирование в остатке трудноокисляемого в ходе сжигания в АФТ сульфида кальция (в противоположность переработке кукерсита). Сульфид же железа, основной продукт разложения пирита, легко выжигается в АФТ.

В дополнение к сказанному полезно сопоставить данные табл. 1 с данными распределения серы при полукоксовании дифференциальнопластовых проб кукерсита в стандартной лабораторной реторте, т. е. также в условиях отсутствия контакта летучих с разложенной карбонатной частью. Переход общей серы в смолу (от 7 до 12\%) и в газ полукоксования (от 25,5 до $38,5 \%$ ) [3] прямо указывает на протекание вторич-

Таблица 2

Баланс распределения серы в аэрофонтанной сушилке пилотной установки при $T_{\mathrm{c}}=225^{\circ} \mathrm{C}$

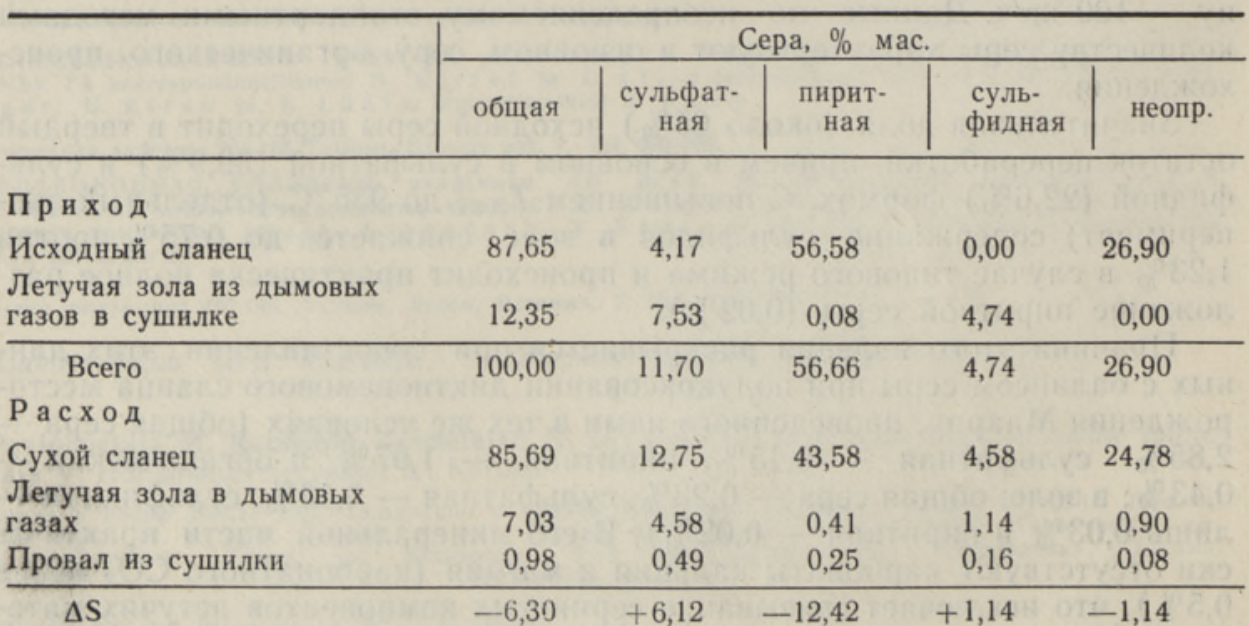


Баланс разспределения серы в реа́кторе пилотной установки при $T_{\mathrm{p}} 515^{\circ} \mathrm{C}$

\begin{tabular}{l|c|c|c|c|c}
\hline & \multicolumn{4}{c}{ Сера, \% мас. } \\
\cline { 2 - 4 } & общая & $\begin{array}{c}\text { сульфат- } \\
\text { ная }\end{array}$ & $\begin{array}{c}\text { пирит- } \\
\text { ная }\end{array}$ & $\begin{array}{c}\text { суль- } \\
\text { фидная }\end{array}$ & неопр. \\
\hline
\end{tabular}

Пр и ход

\begin{tabular}{crrrrr} 
Сухой сланец & 16,51 & 2,46 & 8,40 & 0,88 & 4,77 \\
Теплоноситель & 83,49 & 56,05 & 0,37 & 26,69 & 0,38 \\
\hline Всего & 100,00 & 58,51 & 8,77 & 27,57 & 5,15
\end{tabular}

$\mathrm{P}$ а с $\mathrm{x} о$ д

Твердый остаток

термического разложения $\quad 98,29 \quad 57,04 \quad 4,85 \quad 33,74 \quad 2,66$

Газ полукоксования $\quad 0,02$

Смола $\quad 0,83$

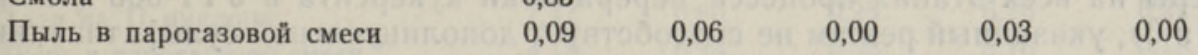

Вода подсмольная

0,01

$\Delta \mathrm{S}$

$-0,76$

$-1,41$

$-3,92+6,20$

$-2,49$

ных реакций в УТТ. Таким образом, значительная часть сульфидной серы в зольном остатке кукерсита в УТТ обусловлена наличием в нем стабильного к термоокислению сернистого кальция.

Рассмотрим балансы серы в основных узлах этой установки. В АФС (табл. 2) благодаря наличию некоторого количества кислорода в сушильном агенте - дымовых газах - происходит заметное окисление части пирита (на $22 \%$ ) и небольшой доли органической серы (на 4,2\%), а также увеличение содержания в сланце сульфатов. В реакторе (табл. 3) разлагается $48,3 \%$ органической серы сланца, доля пиритной серы снижается на $44,7 \%$. Прирост сульфидной формы в твердом остатке втрое превышает количество сульфида в $\mathrm{FeS}$, образующегося за счет разложения пирита в реакторе, что свидетельствует о значительном дополнительном связывании сернистой части летучих в ходе вторичных хемосорбционных процессов. Вторичные же восстановительные реакции

таблица 4

Баланс распределения серы в аэрофонтанной топке пилотной установки при $T_{\mathrm{AФТ}}=875^{\circ} \mathrm{C} ; \alpha=1,2$

\begin{tabular}{c|c|c|c|c|c}
\hline & \multicolumn{4}{c}{ Сера, \% мас. } \\
\cline { 2 - 4 } & общая & $\begin{array}{c}\text { сульфат- } \\
\text { ная }\end{array}$ & $\begin{array}{c}\text { пирит- } \\
\text { ная }\end{array}$ & $\begin{array}{c}\text { суль- } \\
\text { фидная }\end{array}$ & неопр. \\
\hline
\end{tabular}

П р и ход

Твердый остаток

$\begin{array}{llllll}\text { термического разложения } & 100,00 & 58,03 & 4,94 & 34,32 & 2,71\end{array}$

Ра с ход

\begin{tabular}{lrrrrr} 
Зола & 11,65 & 7,10 & 0,08 & 4,47 & 0,00 \\
Теплоноситель & 84,93 & 57,02 & 0,38 & 27,15 & 0,38 \\
Провал из топки & 0,27 & 0,19 & 0,02 & 0,06 & 0,00 \\
\hline \multicolumn{1}{c}{$\Delta \mathrm{S}$} & $-3,15$ & $+6,28$ & $-4,46$ & $-2,64$ & $-2,33$
\end{tabular}

Пр и меча н и е. Разложение карбонатов в АФТ составляет $78,7 \%$. 
при взаимодействии твердого материала с газом полукоксования, как показывает этот баланс, приводят к некоторому снижению сульфатной серы. В АФТ при указанных режимных условиях (табл. 4) происходит выжигание органической и пиритной серы на $86-90 \%$, но термоокислительная конверсия сульфидной серы, по причинам, изложенным выше, дает лишь $7,7 \%$. Две трети выжигаемой в АФТ серы, таким образом, переходит в твердый остаток в виде сульфатов, а одна треть - в газ. При этом степень разложения карбонатов минеральной части, определяющая активность связывания теплоносителем кислых компонентов в реакторе, достигает в АФТ 78,7\%.

Переход к полупромышленной установке с производительностью по сланцу 500 т/сут принес с собой не только увеличение масштаба, но и некоторое усложнение системы удаления золы, а также существенные изменения технологического режима: резкое уменьшение удельного расхода дутья (до $\alpha=0,7)$, снижение температуры (до $825-835^{\circ} \mathrm{C}$ ) в АФТ, необходимость поддержания $T_{\mathrm{p}}$ на уровне $505^{\circ} \mathrm{C}$. Как видно из технохимической характеристики продуктов, а также из общего баланса серы на всех этапах процесса переработки кукерсита в УТТ-500 (табл. 5 и 6), указанный режим не способствует дополнительной сульфатизации твердого остатка. В основной массе золы, выделяемой из I циклона, подавляющая часть серы относится к сульфидной. Согласно общему балансу, почти $90 \%$ исходной серы переходит в твердый остаток, причем доля сульфидной составляющей доходит до $77,5 \%$, а сульфатной - лишь до $6,9 \%$. В полезную часть летучих переходит $7,3 \%$ общей серы, в дымовые газы - только $0,7 \%$ (в виде диоксида серы и сероводорода).

Баланс распределения серы в АФС показывает, что из-за отсутствия свободного кислорода в сушильном агенте термоокислительной конверсии серы в этом узле практически не происходит, если не считать сни-

Таблица 5

Технохимическая характеристика продуктов термической переработки кукерсита в полупромышленной установке УТТ-500

\begin{tabular}{|c|c|c|c|c|c|c|c|}
\hline \multirow[b]{2}{*}{ Проба } & \multirow[b]{2}{*}{$\begin{array}{l}\text { Зола } \\
A d, \\
\% \text { мас. }\end{array}$} & \multirow{2}{*}{$\begin{array}{c}\text { Диоксид } \\
\text { углерода } \\
\left(\mathrm{CO}_{2}\right)^{d}{ }_{M} \\
\% \\
\% \text { мас. }\end{array}$} & \multicolumn{5}{|c|}{ Сера, \% мас. } \\
\hline & & & общая & $\begin{array}{c}\text { сульфат- } \\
\text { ная }\end{array}$ & $\begin{array}{l}\text { пирнт- } \\
\text { ная }\end{array}$ & $\begin{array}{c}\text { сульфид- } \\
\text { ная }\end{array}$ & неопр. \\
\hline Сланец исходный & 48,49 & 17,49 & 2,05 & 0,04 & 1,40 & 0,00 & 0,61 \\
\hline Сланец сухой & 46,40 & 14,96 & 2,06 & 0,04 & 1,38 & 0,04 & 0,60 \\
\hline Зола из I циклона & 86,16 & 16,44 & 3,08 & 0,23 & 0,07 & 2,78 & 0,00 \\
\hline Зола из II циклона & 93,24 & 8,21 & 2,71 & 0,29 & 0,09 & 2,25 & 0,08 \\
\hline $\begin{array}{l}\text { Твердый остаток } \\
\text { термического раз- } \\
\text { ложения (полу- }\end{array}$ & & & & & & & \\
\hline $\begin{array}{l}\text { кокс + теплоно- } \\
\text { ситель) }\end{array}$ & 73,03 & 24,29 & 2,73 & 0,15 & 0,37 & 2,09 & 0,12 \\
\hline Теплоноситель & & & 2,84 & 0,20 & 0,05 & 2,59 & 0,00 \\
\hline $\begin{array}{l}\text { Летучая зола в } \\
\text { дымовых газах }\end{array}$ & 75,47 & 10,67 & 2,06 & 0,18 & 0,87 & 0,81 & 0,20 \\
\hline Подсмольная вода & & & 0,02 & & & & \\
\hline Смола легкая & & & 1,05 & & & & bets \\
\hline $\begin{array}{l}\text { Смола средняя }+ \\
\text { тяжелая }\end{array}$ & & & 0,70 & & & ahe & 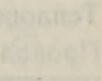 \\
\hline Газовый бензин & & & 0,20 & & & & \\
\hline
\end{tabular}

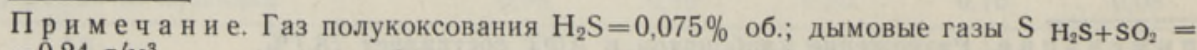
$=0,24 \mathrm{r} / \mathrm{m}^{3}$. 
Общий баланс распределения серы в процессе переработки кукерсита в УТТ-500

\begin{tabular}{|c|c|c|c|c|c|}
\hline & \multicolumn{5}{|c|}{ Сера, \% мас. } \\
\hline & общая & $\begin{array}{l}\text { суль- } \\
\text { фатная }\end{array}$ & $\begin{array}{c}\text { пирит- } \\
\text { ная }\end{array}$ & $\begin{array}{l}\text { суль- } \\
\text { фндная }\end{array}$ & неопр. \\
\hline \multicolumn{6}{|l|}{ Приход } \\
\hline Исходный сланец & 100,0 & 1,95 & 68,29 & 0,00 & 29,76 \\
\hline Р асход & & & & twe $x^{2}$ & and \\
\hline Газ полукоксования & 0,23 & + & & xheres & \\
\hline Газовый бензин & 0,18 & & tata & 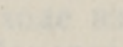 & 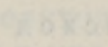 \\
\hline \multicolumn{6}{|l|}{ Смола } \\
\hline $\begin{array}{l}\text { легкая } \\
\text { средняя + тяжелая }\end{array}$ & $\begin{array}{l}4,94 \\
1,93\end{array}$ & & & & \\
\hline Вода подсмольная & 0,05 & & & & \\
\hline Зола из I циклона & 73,54 & 5,49 & 1,67 & 66,38 & 0,00 \\
\hline Зола из II циклона & 7,47 & 0,80 & 0,25 & 6,20 & 0,22 \\
\hline Пыль в парогазовой смеси * & 4,13 & 0,23 & 0,56 & 3,16 & 0,18 \\
\hline \multicolumn{6}{|l|}{$\begin{array}{l}\text { Летучая зола в дымовых } \\
\text { газах при входе в }\end{array}$} \\
\hline $\begin{array}{l}\text { газах при входе в } \\
\text { мультициклоны }\end{array}$ & 4,52 & 0,39 & 1,91 & 1,78 & 0,44 \\
\hline Дымовые газы $\left(\mathrm{H}_{2} \mathrm{~S}+\mathrm{SO}_{2}\right)$ & 0,72 & & & & \\
\hline$\Delta S$ & $-2,29$ & $+4,96$ & $-63,90$ & $+77,52$ & $-28,92$ \\
\hline
\end{tabular}

Из приведенного количества в пылевой камере выделяется $3,82 \%$, в смолу переходит $0,31 \%$.

жения содержания органической серы на $2 \%$. Поэтому более подробные данные такого баланса не приводятся.

Баланс серы в реакторе УТТ-500 (табл. 7) свидетельствует о принципиальном сходстве данных с показателями для пилотной установки. В нем происходит разложение органической серы на $48 \%$ и снижение пиритной составляющей на $34,7 \%$.

Таблица 7

Баланс распределения серы в реакторе УТТ-500 при $T_{\mathrm{p}}=505^{\circ} \mathrm{C}$

\begin{tabular}{|c|c|c|c|c|c|}
\hline \multirow{2}{*}{ 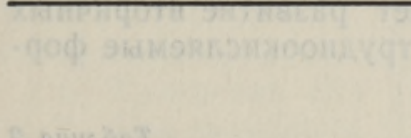 } & \multicolumn{5}{|c|}{ Сера, \% мас. } \\
\hline & общая & $\begin{array}{l}\text { суль- } \\
\text { фатная }\end{array}$ & $\begin{array}{l}\text { пирит- } \\
\text { ная }\end{array}$ & $\begin{array}{l}\text { суль- } \\
\text { фидная }\end{array}$ & неопр. \\
\hline \multicolumn{6}{|l|}{ Приход } \\
\hline Сухой сланец & 28,41 & 0,55 & 19,03 & 0,55 & 8,28 \\
\hline Теплоноситель & 71,59 & 5,04 & 1,26 & 65,29 & 0,00 \\
\hline Bcero & 100,00 & 5,59 & 20,29 & 65,84 & 8,28 \\
\hline \multicolumn{6}{|l|}{$\begin{array}{l}\text { Р асход } \\
\text { Твердый остаток терми- }\end{array}$} \\
\hline $\begin{array}{l}\text { Твердый остаток терми- } \\
\text { ческого разложения }\end{array}$ & 96,53 & 5,30 & 13,08 & 73,90 & 4,25 \\
\hline Пыль в парогазовой смеси & 1,19 & 0,07 & 0,16 & 0,91 & 0,05 \\
\hline Газ полукоксования & 0,07 & & & & 204.946 \\
\hline Газовый бензин & 0,05 & & & $x^{2}$ & 31 en \\
\hline \multicolumn{6}{|l|}{$\begin{array}{l}\text { Смола } \\
\text { легкая }\end{array}$} \\
\hline $\begin{array}{l}\text { легкая } \\
\text { средняя + тяжелая }\end{array}$ & $\begin{array}{l}1,42 \\
0,55\end{array}$ & & & & \\
\hline Вода подсмольная & 0.01 & & & & \\
\hline$\Delta S$ & $-0,18$ & $-0,22$ & $-7,05$ & $+8,97$ & $-3,98$ \\
\hline
\end{tabular}


Баланс распределения серы в аэрофонтанной топке УТТ-500 при $T_{\text {АФТ }}=825^{\circ} \mathrm{C} ; \alpha=0,7$

\begin{tabular}{|c|c|c|c|c|c|c|}
\hline \multirow{2}{*}{ 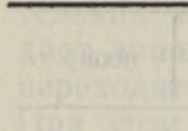 } & \multirow{2}{*}{ 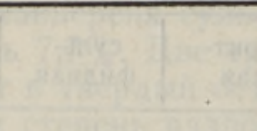 } & \multicolumn{5}{|c|}{ Сера, \% мас. } \\
\hline & & общая & \begin{tabular}{|c|} 
суль- \\
фатная
\end{tabular} & $\begin{array}{l}\text { пирит- } \\
\text { ная }\end{array}$ & $\begin{array}{l}\text { суль- } \\
\text { фидная }\end{array}$ & неопр. \\
\hline
\end{tabular}

Пр иход

Твердый остаток термического разложения

Р а с х о

Зола из I циклона

Зола из II циклона

Теплоноситель

Летучая зола в дымовых газах

Дымовые газы $\left(\mathrm{H}_{2} \mathrm{~S}+\mathrm{SO}_{2}\right)$

$\Delta S$

$\begin{array}{rrrrr}100,00 & 5,50 & 13,55 & 76,55 & 4,40 \\ & & & & \\ 21,87 & 1,63 & 0,50 & 19,74 & 0,00 \\ 2,22 & 0,24 & 0,07 & 1,84 & 0,07 \\ 74,42 & 5,22 & 1,31 & 67,89 & 0,00 \\ 1,18 & 0,13 & 0,04 & 0,98 & 0,03 \\ 0,22 & & & & \end{array}$

$\Delta S$

$-0,09$

$+1,72$

$-11,63 \quad+13,90$

$-4,30$

Пр и ме ч ан и е. Разложение карбонатов в АФТ составляет $47,6 \%$.

Наибольший интерес представляют изменения в распределении разновидностей серы, обусловленные термоокислением в АФТ (табл. 8). Органическая сера выжигается почти полностъю, пиритная форма разлагается на $86 \%$. Наряду с приростом сульфатной разновидности (всего лишь на $1,7 \%$ ) возрастает и доля сульфидов - на $13,9 \%$ (от $\left.\mathrm{S}_{\text {общ}}\right)$. Наиболее вероятным источником такого перераспределения можно считать своеобразный побочный процесс «дококсования» твердого остатка, поступающего из реактора, который сопровождает его неполное сжигание в топке. В результате термической деструкции остаточного пирита не только увеличивается содержание сульфидной формы в золе, но и одновременно обнаруживается сероводород в дымовых газах (в количестве до $\left.0,22 \mathrm{r} / \mathrm{m}^{3}\right)$. Добавим, что степень разложения карбонатов минеральной части в этих условиях в АФТ снижается до $47,6 \%$.

Таким образом, сжигание твердого остатка в АФТ полупромышленной установки УТТ-500 отнюдь не ограничивает развитие вторичных реакций в системе, в ходе которых образуются трудноокисляемые фор-

Таблица 9

Технохимическая характеристика продуктов технической переработки кукерсита в промышленной установке УТТ-3000 при $T_{\mathrm{AФT}}=740-750^{\circ} \mathrm{C}$ и $T_{\mathrm{p}}=500^{\circ} \mathrm{C}$

\begin{tabular}{|c|c|c|c|c|c|c|c|}
\hline \multirow[b]{2}{*}{ Проба } & \multirow[b]{2}{*}{$\begin{array}{l}\text { Зола } A^{d}, \\
\% \text { мас. }\end{array}$} & \multirow{2}{*}{ 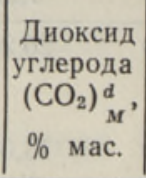 } & \multicolumn{5}{|c|}{ Сера, \% мac. } \\
\hline & & & общая & $\begin{array}{c}\text { сульфат- } \\
\text { ная }\end{array}$ & $\begin{array}{l}\text { пирит- } \\
\text { ная }\end{array}$ & $\begin{array}{c}\text { сульфид- } \\
\text { ная }\end{array}$ & неоп. \\
\hline Сланец исходный & 49,56 & 22,42 & 1,60 & 0,06 & 1,08 & 0,00 & 0,46 \\
\hline Зола из I циклона & 67,22 & 31,23 & 1,39 & 0,47 & 0,13 & 0,79 & 0,00 \\
\hline Зола из II циклона & 74,76 & 17,67 & 1,36 & 0,43 & 0,21 & 0,72 & 0,00 \\
\hline $\begin{array}{l}\text { Зола нз III цик- } \\
\text { лона } \\
\text { Пыль в дымовых }\end{array}$ & 79,86 & 13,31 & 1,55 & 0,72 & 0,25 & 0,58 & 0,00 \\
\hline $\begin{array}{l}\text { газах (до } \\
\text { электрофнльтра) }\end{array}$ & 78,47 & 12,00 & 1,14 & & & & \\
\hline
\end{tabular}


мы серы, и не обеспечивает снижение наиболее вредных веществ в выбросах. Под этим углом полезно рассмотреть предварительную технохимическую характеристику материалов, помогающую создать качественное представление о распределении серы при термической переработке сланца с твердым теплоносителем в опытной промышленной установке УТТ-3000 (табл. 9). Пробы отобраны в период длительных испытаний одного из наиболее реальных режимов переработки. Детальный же баланс серы не приводится, поскольку стадия опытных работ еще не завершена и окончательный выбор оптимального режима пока не сделан.

Характерным для использованного режима является относительно низкий температурный потенциал сжигания твердого остатка в АФТ $\left(740-750{ }^{\circ} \mathrm{C}\right)$ при обычной температуре смеси на выходе из реактора. В связи с этим щелочные продукты разложения карбонатов кальция в твердом зольном остатке, на основе которого формируется теплоноситель, практически отсутствуют. Это сводит почти на нет вторичные реакции связывания сернистых компонентов летучих до сернистого кальция, устойчивого к термоокислению. Содержащиеся в «низкотемпературной золе» сульфиды представляют собой в основном продукт термического разложения пирита, которое, очевидно, завершается в АФТ. Содержание сульфидов в выводимом из АФТ твердом материале оказывается в 3-4 раза ниже, чем в условиях УТТ-500.

\section{Выводы}

1. На основе экспериментального изучения приведены балансы распределения разновидностей серы на основных этапах переработки сланца-кукерсита в установках с твердым теплоносителем различной мощности.

2. Наряду со специфической химической природой разновидностей серы и важнейших компонентов минеральной части кукерсита, на их трансформацию и распределение существенное воздействие оказывают такие факторы, как температура в каждом технологическом узле и избыток (либо недостаток) воздушного дутья. Их варьирование способствует либо развитию, либо ограничению вторичных реакций взаимодействия твердого материала с сернистыми компонентами летучих.

\section{Л И Т Е Р А Т Р А}

1. Термическая переработка сланца-кукерсита. Под ред. М. Я. Губергрица. Таллин, 1966.

2. Торпан Б. К. О химическом и минералогическом составе пластов и пропластов кукерсита. - Тр. Таллин. политехн. ин-та, $1957,57,22-31$.

3. Губергриц М. Я., Эленурм А. А. Распределение и трансформация разновидностей серы при полукоксовании сланца-кукерсита. - Инф. сер. I, Горючие сланцы, $1981,4,11-19$.

$$
\begin{gathered}
\text { Институт химии } \\
\text { Академии наук Эстонской ССР }
\end{gathered}
$$

Государственный научно-исследовательский энергетический институт им. Г. М. Кржижсановского 
A. ELENURM, M. MARGUSTE, I. ROHTLA, T. VESKIOJA, M. GUBERGRITS,

V. TSIKUL, B. TJAGUNOV

\section{VÄÄVLI JAGUNEMINE KUKERSIIDI TERMILISEL TÖÖTLEMISEL TAHKE SOOJUSKANDJAGA SEADMETES}

Eksperimentaaluuringute alusel on käsitletud erinevate väävliühendite jagunemist peeneteralise kukersiidi termilisel töötlemisel tahke soojuskandjaga seadmetes. Soojuskandjana on kasutatud töödeldava põlevkivi tuhka.

Väävlibilansi analüüsil ilmneb põhiliste tegurite (seadme tehnoloogiliste sõlmede temperatuuri, poolkoksi põletamisel koldesse antava ôhu hulga) toime, mis lähteaine keemilise iseloomu kõrval avaldab mõju väävli jagunemisele ja transformeerumisele tehnoloogilise protsessi üksiketappidel.

A. ELENURM, M. MARGUSTE, I. ROHTLA, T. VESKIOJA, M. GUBERGRITS, W. TSCHIKUL, B. TJAGUNOW

\section{DIE VERTEILUNG DES SCHWEFELS BEI DER THERMISCHEN VERARBEITUNG VON KUCKERSIT IN DEN ANLAGEN MIT FESTEM WÄRMETRÄGER}

Auf Grund der experimentellen Untersuchungen wird die Verteilung von verschiedenen Schwefelverbindungen bei der thermischen Verarbeitung des kleinkörnigen Kuckersits in den Anlagen des festen Wärmeträgers behandelt. Als Wärmeträger dient die Asche desselben Brennschiefers.

Aus der Zerlegung von Schwefelbilanzen ergeben sich ausschlaggebende Faktoren (Temperaturbedingungen in den technologischen Trakten der Anlage, Luftmenge bei der Verbrennung des Halbkokses in der Feuerungsanlage), die neben dem chemischen Charakter des Ausgangsstoffes die Verteilung und Transformation des Schwefels in Einzeletappen des technologischen Prozesses beeinflussen. 